\title{
Patient perceptions of participation in emergency medicine research projects
}

(Running head: Patient perceptions of research)

Erik J de Tonnerre BMedSci MD ${ }^{1}$

edetonnerre@gmail.com

Jesse L Smith BSci MD²

jesse.lachlan.smith@gmail.com

William S Spencer BMedSci MD ${ }^{3}$

Willsspencer1@gmail.com

Patrick A Date BSci MD ${ }^{4}$

patrick.a.date@gmail.com

David McD Taylor MD DRCOG MPH FACEM ${ }^{5,6}$

David.Taylor@austin.org.au

${ }^{1}$ Intern, Northern Sydney Local Health District, NSW Health, NSW, Australia

${ }^{2}$ Intern, Central Gippsland Health, Sale, Victoria, Australia

${ }^{3}$ Intern, Alfred Health, Commercial Road, Melbourne, Victoria, Australia

${ }^{4}$ Intern, Austin Hospital, Studley Road, Heidelberg, Victoria, Australia

${ }^{5}$ Director of Emergency Medicine, Emergency Department, Austin Hospital, Studley Road, Heidelberg, Victoria, Australia

${ }^{6}$ Professor, Department of Medicine, University of Melbourne, Parkville, Victoria, Australia

\section{Corresponding Author:}

Professor David Taylor

Emergency Department, Austin Hospital

Studley Road, Heidelberg, Victoria, Australia 3084

Phone (W) +61 394964711

David.Taylor@austin.org.au

\section{Author Contributions:}

EdeT and DT developed the protocol for the project. DT obtained ethics committee approval. EdeT, JS, WS and PD collected all the data. All authors assisted DT in data analysis and interpretation. All authors contributed to drafting and critical revision of the manuscript. DT supervised the project overall. All authors take responsibility for the manuscript.

\begin{abstract}
This is the author manuscript accepted for publication and has undergone full peer review but has not been through the copyediting, typesetting, pagination and proofreading process, which may lead to differences between this version and the Version of Record. Please cite this article as doi: 10.1111/1742-6723.13455
\end{abstract}

This article is protected by copyright. All rights reserved. 


\section{Objective}

To determine if ED research reflects patient expectations

\section{Methods}

A cross-sectional ED patient survey.

\section{Results}

309 (98.1\%, 95\%CI 95.7-99.2) of 315 patients believed that ED research was important. 212 (68.4\%, 95\%CI 62.9-73.5) would welcome involvement only 26 (8.4\%, 95\%CI 5.7-12.3) felt pressured to do so. 231 (75.7\%, 95\%CI 70.5-80.4) and 279 (91.5\%, 95\%CI 87.6-94.3) believed consent was necessary for observational and experimental studies, respectively. 101 (32.4\%, 95\%CI 27.3-37.9) disagreed with medical records being accessed without consent.

\section{Conclusion}

Patient expectations are not always consistent with current practice. The expectation of consent prior to record access is worthy of further consideration.

Keywords: emergency department, research, ethics, informed consent, 


\section{INTRODUCTION}

Medical research is required to expand knowledge and inform management best-practice. ${ }^{1}$ Research in the unique ED setting is usually clinical, often requiring patient participation.

However, patients are often acutely unwell. Few studies have examined patients’ perceptions of research in this setting. Although well supported by the public in the United States ${ }^{2}$ and United Kingdom $^{1}$, little is known of the perceptions of Australasian patients. We aimed to determine these perceptions across a range of domains including the value of ED research, willingness to participate, the consent process, information provision and perceived barriers and facilitators.

This article is protected by copyright. All rights reserved. 


\section{METHODS}

This was a voluntary, anonymous, cross-sectional survey of patients presenting to a tertiary ED (February-June 2018). It was approved by the institution’s Human Research Ethics Committee. Convenience sampling (9:00-17:00, Monday-Friday) of consecutive patients was undertaken (selection bias possible). Patients were excluded if they were aged $<18$ years, lacked capacity to consent, did not speak English or were too ill (as determined by the ED staff).

The study questionnaire was patient-administered, with assistance if necessary. It was designed for the study with questions of particular relevance to ED patients, as informed by the medical literature (see Appendix). It was examined for face-validity on six ED patients and no revision was required. Data were collected on previous ED research participation, perceptions of ED research, the nature of information that should be provided and the nature of consent for audit, observational and experimental studies.

The primary outcome was patient willingness to be involved in ED research. Secondary outcomes were perceptions about information provision and the consent process. Analysis of responses was descriptive (percentages, 95\%CIs) and patient subgroups were compared using the Chi square test.

This article is protected by copyright. All rights reserved. 


\section{RESULTS}

315 (86.8\%) of 363 suitable patients participated: 165 (52.4\%) males, 147 (46.7\%) aged 41-65 years inclusive, 214 (67.9\%) Australasian/British and 16 (5.1\%) with previous research participation.

Overall, 212 (68.4\%, 95\%CI 62.9-73.5) patients would welcome the opportunity to be involved in research (Table). The responses of male and female did not differ $(p=0.61)$ although older patients were less likely to welcome involvement $(\mathrm{p}=0.03$, disagree/strongly disagree responses merged). 309 (98.1\%, 95\%CI 95.7-99.2) patients believed that research was important and only 26 (8.4\%, 95\%CI 5.7-12.3) would feel pressured to participate. 101 (32.4\%, 95\%CI 27.3-37.9) disagreed with medical records being accessed without consent. 148 (48.4\%, 95\%CI 42.7-54.1) reported that delayed consent due to time pressures was acceptable and 208 (68.0\%, 95\%CI 62.4-73.1) reported that participants should receive the study results.

More patients reported that written or verbal information about the study should be given for experimental studies $(\mathrm{p}<0.001)$ although substantial proportions believed that both types of information should be given (Figure). Patient perceptions regarding the consent process for observational and experimental studies differed. Most patients reported that consent should be obtained before enrolment, especially in experimental studies $(\mathrm{p}<0.001)$. Most patients believed that written consent should be obtained, especially for experimental studies $(\mathrm{p}<0.001)$.

This article is protected by copyright. All rights reserved. 
Patients suggested that future ED research should be directed at specific conditions, ED efficiency and the safety of health workers. Concerns regarding research participation included privacy, risk and time commitment.

This article is protected by copyright. All rights reserved. 


\section{DISCUSSION}

It is encouraging that almost all patients believed that ED research was important, that two thirds would welcome participation and that few would feel pressured. Overall, ED patients are more receptive of research than the general public ${ }^{2,3}$ although our patients' concerns about participation are similar to those reported elsewhere. ${ }^{4}$

Information regarding research risk and benefit is important to patients. Written or verbal information, or both, was expected by our patients, especially written information for experimental studies.

Almost all patients agreed that informed consent was required, a finding reported elsewhere. ${ }^{2,3}$ Written consent was seen as superior to verbal alone, especially for experimental studies. Patients place greater emphasis on the consent process as risk increases. ${ }^{3}$ One half of patients believed that delayed consent may be acceptable, a finding consistent with that of Smithline et al. ${ }^{3}$

The almost universal practice of accessing medical records without consent was unacceptable to one third of patients. However, Whiteman et al. ${ }^{5}$ reported that most Australians supported audit studies without consent. Again, ED patient perceptions may differ from the general public.

This article is protected by copyright. All rights reserved. 
Current ED research best-practice includes both verbal and written information provision and, in all but low risk research, written patient consent. This practice is consistent with our patients' expectations. However, the need for consent to access medical records, as expressed by many, is not usual practice and should be explored further. As the majority of patients would welcome a summary of their study's results, consideration should be given to this expectation. 


\section{ACKNOWLEDGEMENTS}

Nil

\section{CONFLICTS OF INTERESTS}

None declared

This article is protected by copyright. All rights reserved. 


\section{REFERENCES}

1. Booth MG, Lind A, Read E, Kinsella J. Public perception of emergency research: a questionnaire. EJA 2005; 22: 933-7

2. Biros MH, Sargent C, Miller K. Community attitudes towards emergency research and exception from informed consent. Resuscitation 2009; 80: 1382-7

3. Smithline HA, Gerstle ML. Waiver of informed consent: A survey of emergency medicine patients. AmJEM 1998; 16: 90-1

4. Limkakeng AT, de Oliveira LLH, Moreira T et al. Systematic review and metasummary of attitudes toward research in emergency medical conditions. $J$ Med Ethics 2014; 40: 401-8

5. Whiteman DC, Clutton C, Hill D. Australian public's views on privacy and health research. BMJ 2006; 332: 1274

This article is protected by copyright. All rights reserved. 
Table. Patient perceptions of research participation

\begin{tabular}{|c|c|c|c|c|c|c|}
\hline item & $\begin{array}{c}\text { patient } \\
\text { subgroups }\end{array}$ & $\begin{array}{c}\text { strongly } \\
\text { agree } \\
\text { n (\%) }\end{array}$ & $\begin{array}{l}\text { agree } \\
\text { n (\%) }\end{array}$ & $\begin{array}{c}\text { neutral } \\
\text { n (\%) }\end{array}$ & $\begin{array}{c}\text { disagree } \\
n(\%)\end{array}$ & $\begin{array}{c}\text { strongly } \\
\text { disagree } \\
\text { n (\%) }\end{array}$ \\
\hline
\end{tabular}

I would welcome the opportunity to be involved in ED research $(n=310)$ :

$\begin{array}{cccccc}\text { male } & 38(23.2) & 71(43.3) & 47(28.7) & 6(3.7) & 2(1.2) \\ \text { female } & 39(26.7) & 64(43.8) & 33(22.6) & 9(6.2) & 1(0.7) \\ 18-40 & 22(25.6) & 35(40.7) & 26(30.2) & 2(2.3) & 1(1.2) \\ 41-65 & 37(25.5) & 69(47.6) & 35(24.1) & 4(2.8) & 0(0.0) \\ >65 \text { years } & 18(22.8) & 31(39.2) & 19(24.1) & 9(11.4) & 2(2.5)\end{array}$

Overall, I believe research in the ED is important $(n=315)$ :

$$
195(62.9) \quad 114(36.2) \quad 6(1.9) \quad 0(0.0) \quad 0(0.0)
$$

I would feel pressured to participate in ED research $(n=308)$ :

$$
6(1.9) \quad 20(6.5) \quad 90(29.2) \quad 112(36.4) \quad 80(26.0)
$$

Accessing a patient's record without consent is acceptable for research $(n=312)$ :

$$
52(16.7) \quad 109(34.9) \quad 50(16.0) \quad 51(16.3) \quad 50(16.0)
$$

If there is no time, it is acceptable to enrol a patient and consent later $(n=306)$ :

$$
51(16.7) \quad 97(31.7) \quad 72(23.5) \quad 60(19.6) \quad 26(8.5)
$$

Participants should receive the results of a study they participate in $(n=306)$ :

$$
90(29.4) \quad 118(38.6) \quad 86(28.1) \quad 10(3.3) \quad 2(0.7)
$$




\section{Figure Legend}

Figure. Patient perceptions of consent for observational and experimental studies

This article is protected by copyright. All rights reserved. 


\section{University Library}

\section{- M M I N E R VA A gateway to Melbourne's research publications}

Minerva Access is the Institutional Repository of The University of Melbourne

Author/s:

De Tonnerre, EJ;Smith, JL;Spencer, WS;Date, PA;Taylor, DM

Title:

Patient perceptions of participation in emergency medicine research projects

Date:

2020-02-10

Citation:

De Tonnerre, E. J., Smith, J. L., Spencer, W. S., Date, P. A. \& Taylor, D. M. (2020). Patient perceptions of participation in emergency medicine research projects. EMERGENCY MEDICINE AUSTRALASIA, 32 (4), pp.570-572. https://doi.org/10.1111/1742-6723.13455.

Persistent Link:

http://hdl.handle.net/11343/275388 